\title{
Growth mechanism and pH-regulation characteristics of composite latex particles prepared from Pickering emulsion polymerization of aniline/ZnO using different hydrophilicities of oil phases
}

\author{
Jauder Jeng $^{\text {a }}$, Tai-You Chen ${ }^{b}$, Chia-Fen Lee ${ }^{c}$, Nai-Yun Liang ${ }^{d}$, Wen-Yen Chiu ${ }^{\text {a,b,e,* }}$ \\ ${ }^{a}$ Institute of Polymer Science and Engineering, National Taiwan University, Taipei, 106 Taiwan, ROC \\ ${ }^{\mathrm{b}}$ Department of Chemical Engineering, National Taiwan University, Taipei, Taiwan, ROC \\ ${ }^{\mathrm{C}}$ Department of Cosmetic Science, Chia Nan University of Pharmacy and Science, Tainan, Taiwan, ROC \\ ${ }^{\mathrm{d}}$ Taiwan Textile Research Institute, Taipei, 236 Taiwan, ROC \\ e Department of Materials Science and Engineering, National Taiwan University, Taipei, Taiwan, ROC
}

\section{A R T I C L E I N F O}

\section{Article history:}

Received 18 March 2008

Received in revised form 16 May 2008

Accepted 18 May 2008

Available online 22 May 2008

\section{Keywords:}

Pickering emulsion polymerization

Polyaniline

$\mathrm{ZnO}$ nanoparticles

\begin{abstract}
A B S T R A C T
A Pickering emulsion polymerization of aniline, using different hydrophilicities of oil phases, was stabilized by $\mathrm{ZnO}$ nanoparticles and performed to synthesize composite latex particles of polyaniline/ZnO. Ammonium peroxydisulfate (APS) was used as an oxidizing agent. The morphologies and growth mechanisms of the resulted composite latex particles were studied. The pH-regulation capacity of the composite latex particles was discussed. When toluene was used as the oil phase, the composite latex particles showed hollow structure, irregular morphology, and hundreds of nanometer in size. It was ascribed to the polymerization of aniline on the interfaces of droplets/water. $\mathrm{ZnO}$ nanoparticles, with $50-100 \mathrm{~nm}$ in size, acted as surfactants to stabilize the emulsion. When THF was used as an oil phase, the composite latex particles showed spherical morphology and enwrapping $\mathrm{ZnO}$ nanoparticles. It was attributed to the homogeneous nucleation of polyaniline in the aqueous phase. $\mathrm{ZnO}$ nanoparticles acted as templates for the polyaniline particles. The stability of the Pickering emulsion polymerization was affected by the volume ratio of the oil phase to water. The aqueous solution with $\mathrm{pH} 3-9$ could simply be regulated to about $\mathrm{pH} 7$ by the composite latex particles. It was contributed by the dissolution of $\mathrm{ZnO}$ nanoparticles and doping-dedoping of polyaniline in the acidic and alkaline aqueous solutions.
\end{abstract}

(c) 2008 Elsevier Ltd. All rights reserved.

\section{Introduction}

An emulsion which is stabilized by only fine solid powders is often referred to as a Pickering emulsion. It has been proven by many recent reports that inorganic nanoparticles can serve as good emulsifiers in formation and stabilization of the Pickering emulsion because of their large surface area [1-10] and hydrophilic groups on their surfaces. In preparation of the emulsion, the inorganic nanoparticles spontaneously self-assemble on surfaces of oil droplets to form a core-shell structure to impede collision coalescence of the droplets [8,9,11-13]. The effectiveness of the inorganic nanoparticles in stabilizing the emulsion depends on the particle shape, size, concentration, and surface hydrophilic groups [1,14].

The stability of the Pickering emulsion also depends on a volume ratio of an oil phase to an aqueous phase [1,5-7,15]. When the volume ratio is too small, the oil phase is completely dissolved. On

\footnotetext{
* Corresponding author. Institute of Polymer Science and Engineering, National Taiwan University, Taipei, 106 Taiwan, ROC. Tel./fax: +886223623259.

E-mail address: ycchiu@ntu.edu.tw (W.-Y. Chiu).
}

the other hand, the droplets are aggregated when the volume ratio is too large. The sizes of the droplets and latex particles depend on a mass ratio of the inorganic nanoparticles to a monomer $[1,9,16]$. As the mass ratio increases, the particle sizes decrease and are distributed in a narrower range.

The Pickering emulsion has been proven to be a feasible route for synthesizing an organic/inorganic hybrid with a unique nanostructure. Xiao and coworkers [1] prepared polyaniline/ $/ \mathrm{Fe}_{3} \mathrm{O}_{4}$ nanocomposites in an acetic aqueous solution and under ultrasonication. Particles with granular and fibrous morphologies were obtained. Chen et al. [3] used an oil-soluble initiator and under strong agitation synthesized polystyrene/ $/ \mathrm{TiO}_{2}$ nanocomposites. The hollow and spherical particles were resulted. Voorn et al. [4] used an inverse Pickering emulsion method to prepare latex particles, armored by clay nanoparticles. Cauvin et al. [10] also prepared the clay-armored latex particles of polystyrene through a Pickering emulsion route. He and coworkers [2,5,9] synthesized polyaniline composites with different nanostructures by simply changing varieties of reaction media and the inorganic nanoparticles. 
In literature, inorganic nanoparticles, ranged from dozens of nanometers to several hundred nanometers in size, were widely used in the Pickering emulsion polymerization. ZnO with relatively large size was used in our work. The polymerization systems with smaller sizes of $\mathrm{ZnO}$ nanoparticles were also done for comparison in our lab. The composite particles decreased in size due to better emulsifying ability of the ZnO nanoparticles with smaller particle sizes.

Polyaniline always receives great attentions because of its easy synthesis, environmental stability, and reversible doping-dedoping chemistry in aqueous solution [17-21]. ZnO is one of the most important nanoparticles, owing to its $\mathrm{pH}$-regulation ability and unique catalytic, optical, electrical, and electronic properties $[22,23]$. Both materials were chosen in our work to study the Pickering emulsion polymerization.

Polyaniline/ZnO composite particles, obtained from our work, will be used as a pH buffering agent for textile application. They will be added in PET powder through a blending process, and finally a pH buffering fiber will be manufactured through a fiber spinning process.

Toluene (relatively insoluble in water) and THF (very soluble in water) were separately used as an oil phase to study the growth mechanisms and morphologies of the composite latex particles in the Pickering emulsion polymerization. Two growth mechanisms of the composite latex particles were proposed. The $\mathrm{pH}$-regulation capacity of the polyaniline/ZnO composite latex particles was discussed.

\section{Experimental}

\subsection{Chemicals}

Aniline (ACROS) was distilled under a reduced pressure and stored at $-15^{\circ} \mathrm{C}$ before use. Zinc acetate dihydrate, sodium hydroxide, ammonium peroxydisulfate (APS), toluene, tetrahydrofuran (THF), propylene glycol methyl ether acetate (PGMEA), and hydrochloric acid were all purchased from ACROS and used as received. Deionized water was used.

\subsection{Preparation of dispersion of $\mathrm{ZnO}$ nanoparticles}

ZnO nanoparticles were synthesized by precipitation from an aqueous phase [24-28]. An aqueous solution, containing $1.756 \mathrm{~g}$ of zinc acetate dihydrate and $300 \mathrm{ml}$ of the deionized water, was heated to $55^{\circ} \mathrm{C}$. Another $100 \mathrm{ml}$ of the deionized water, containing $0.64 \mathrm{~g}$ of sodium hydroxide, was mixed with the above warming aqueous solution. Subsequently, the mixture was reacted for $1 \mathrm{~h}$. The product was purified by centrifugation and then redispersed in $150 \mathrm{ml}$ of the deionized water by an ultrasonic device. The final aqueous dispersion with ca $0.3 \mathrm{~g}$ of $\mathrm{ZnO}$ nanoparticles was resulted. The yield of the $\mathrm{ZnO}$ nanoparticles ( $\sim 38 \%$ ) was not high because of unavoidable weight loss in the purification, but the yield in each batch was reproducible in our work.

\subsection{Preparation of composite latex particles of polyaniline/ZnO}

Composite latex particles of polyaniline/ZnO were synthesized by Pickering emulsion polymerization, stabilized by the $\mathrm{ZnO}$ nanoparticles. A typical preparation procedure and the reaction conditions are detailed as the following. An oil phase, containing $0.36 \mathrm{~g}$ of aniline and $10.5 \mathrm{ml}$ of toluene (or THF), and an aqueous phase, containing $150 \mathrm{ml}$ of the $\mathrm{ZnO}$ aqueous dispersion and $0.6 \mathrm{~g}$ of APS, were mixed by a magnetic stir bar for pre-emulsification. Then the pre-emulsion was ultrasonicated (maximum sonic power density $=460 \mathrm{~W} / \mathrm{cm}^{2}$, Ultrasonic Processor $50 \mathrm{H}$, Dr. Dielsher) in an ice bath for $30 \mathrm{~min}$ to prepare a Pickering emulsion. The amplitude of the ultrasonication was set at $100 \%$. The emulsion was, subsequently, discharged into a reactor to conduct the polymerization at $20^{\circ} \mathrm{C}$ in an ultra-pure nitrogen gas atmosphere for $24 \mathrm{~h}$. The product latex was discharged into a separatory funnel and left for $6 \mathrm{~h}$ to separate a precipitate and to collect stable latex. The stable latex was, finally, purified by dialysis for 7 days.

\subsection{Characterization}

Transmission electron microscope (TEM, JSM-1200 EXIL TEM, JEOL) was used to examine morphologies of the $\mathrm{ZnO}$ nanoparticles and the composite latex particles. An X-ray diffraction (XRD) pattern of the $\mathrm{ZnO}$ nanoparticles was obtained by a Philips X'pert diffractometer at a scanning rate of $0.02^{\circ} / \mathrm{s}$ in the $2 \theta$ range of $25-80$. The diffractometer was equipped with a graphite, monochromatized $\mathrm{Cu} \mathrm{K} \alpha$ radiation in $\lambda=1.5405 \AA$. Thermogravimetric analysis (TGA) was performed by a thermal analyzer (TGA-7, Perkin Elmer) in static air. Each dehydrated sample $(10 \mathrm{mg})$ was heated in an alumina crucible at $10^{\circ} \mathrm{C} / \mathrm{min}$ between 100 and $800{ }^{\circ} \mathrm{C}$.

\subsection{Evaluations of $\mathrm{pH}$-regulation capacities of $\mathrm{ZnO}$ and composite latex particles}

Five stock aqueous solutions in which pH values were ca 3, 5, 7, 9 , and 11 , respectively, were prepared by deionized water and hydrochloric acid (or sodium hydroxide) aqueous solution. Each stock solution $(10 \mathrm{ml})$ was separately discharged into five glass bottles. The composite latex particles or $0.01 \mathrm{~g}$ of $\mathrm{ZnO}$ was then added into each of the five bottles. The bottles were sealed and ultrasonicated for $10 \mathrm{~min}$ to prepare five testing aqueous solutions. The $\mathrm{pH}$ values of the testing solutions were measured by a $\mathrm{pH}$ meter (F-51, HORIBA) at different times. In each set of experiments, at least three measurements were repeated and the averaged steady-state value was taken. The deviation of the measured $\mathrm{pH}$ values was within \pm 0.3 in our results.

\section{Results and discussion}

\subsection{Synthesis of $\mathrm{ZnO}$ nanoparticles}

$\mathrm{ZnO}$ nanoparticles were precipitated from an aqueous phase in synthesis and characterized by TEM and XRD, shown in Figs. 1 and 2 , respectively. The TEM image exhibits that the $\mathrm{ZnO}$ nanoparticles are polyhedral in morphology and $50-100 \mathrm{~nm}$ in size. The XRD pattern exhibits that they are hexagonal lattice. It is consistent with the result in literature $[5,9,29,30]$.

\subsection{Pickering emulsion polymerization of aniline}

Pickering emulsion polymerization of aniline, using different hydrophilicities of oil phases, was stabilized by ZnO nanoparticles and performed to synthesize composite latex particles of polyaniline/ZnO. Toluene and THF were separately used as an oil phase, and volume ratios of the oil phases to water were kept at 0.07 in the Pickering emulsion polymerization, as listed in Table 1. Interestingly, morphologies of both resulted composite latex particles, observed by TEM and shown in Fig. 3a, were largely different. When toluene (relatively insoluble in water) was used as an oil phase, hollow composite latex particles with an irregular shape and 200-700 nm in size, roughly estimated from TEM images and shown in Fig. 3a-i, were obtained. It implied that the polymerization of aniline occurred on the interfaces of droplets/water. $\mathrm{ZnO}$ nanoparticles acted as surfactants in stabilizing the emulsion. However, solid latex particles, enwrapping $\mathrm{ZnO}$ nanoparticles and ranged from 200 to $400 \mathrm{~nm}$ in size, were resulted when THF (very soluble in water) was used as the oil phase. TEM images are shown 


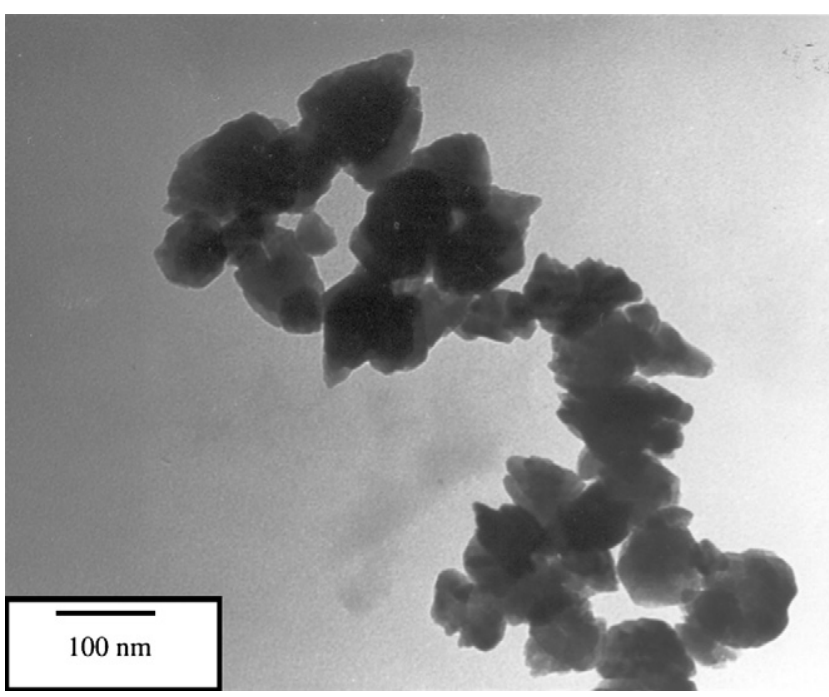

Fig. 1. TEM image of $\mathrm{ZnO}$ nanoparticles which were synthesized from an aqueous phase.

in Fig. 3a-ii. It was attributed to the homogeneous nucleation of polyaniline in the aqueous phase. $\mathrm{ZnO}$ nanoparticles acted as templates for the nucleated particles of polyaniline. The growing particles coagulated from time to time to reduce the surface energy of the system. Solid spherical latex particles, enwrapping $\mathrm{ZnO}$ nanoparticles, were thus formed. From the above results, it was clear that the hydrophilicity of the oil phase strongly influenced the growth mechanism of the composite latex particles.

When toluene was used as the oil phase, the volume ratio of toluene to water $(R)$ was varied from $0.03,0.07$, to 0.13 , as listed in Table 1 , respectively, in order to study the influence of the volume ratio on morphology of the composite latex particles. As $R=0.03$, hollow composite latex particles with several hundred nanometers in size, shown in Fig. 3b-i, were resulted. The morphology was similar to that in run 1 in Table 1 with $R=0.07$. It implied that a stable latex with similar morphology of the composite latex particles could be achieved when $R=0.03-0.07$. While $R=0.13$, a phase-separated composite latex was resulted. The final composite latex was divided into a suspension and a precipitate. The TEM image of the suspension particles is shown in Fig. 3b-ii. It indicated that the volume of oil droplets was too large to be stabilized properly by $\mathrm{ZnO}$ nanoparticles. Therefore, some of the growing particles coagulated and formed polyaniline/ZnO precipitates [1,5-7].

\subsection{TGA analysis}

Composite latex particles, synthesized by separately using toluene and THF as the oil phase, were analyzed by TGA to determine their thermal properties. Both the volume ratios of toluene to water and THF to water were fixed at 0.07, listed in runs 1 and 2 in Table 1

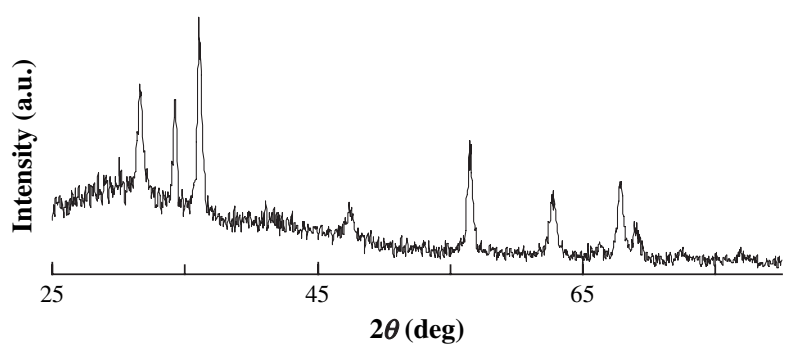

Fig. 2. X-ray diffraction pattern of $\mathrm{ZnO}$ nanoparticles.
Table 1

Reaction parameters and characterization of the Pickering emulsion polymerization of aniline $\mathrm{a}^{\mathrm{a}}$

\begin{tabular}{llll}
\hline Run & Oil phase & $\begin{array}{l}\text { Volume ratio } \\
\text { of oil phase } \\
\text { to water }\end{array}$ & $\begin{array}{l}\text { Morphologies of composite } \\
\text { latex particles }\end{array}$ \\
\hline 1 & Toluene & 0.07 & $\begin{array}{l}\text { Hollow structure } \\
\text { and irregular composite particles } \\
\text { Solid spherical } \\
\text { particles enwrapping ZnO nanoparticles } \\
\text { Hollow structure } \\
\text { and irregular composite particles } \\
\text { Phase separation } \\
\text { into a suspension } \\
\text { and a precipitate }\end{array}$ \\
\hline
\end{tabular}

a The Pickering emulsion polymerization was formulated by $150 \mathrm{~g}$ of an aqueous dispersion containing $0.3 \mathrm{~g}$ of $\mathrm{ZnO}$ nanoparticles, $0.6 \mathrm{~g}$ of APS, and $0.36 \mathrm{~g}$ of aniline in the oil phase. The polymerization was conducted at $20{ }^{\circ} \mathrm{C}$ in an ultra-pure nitrogen gas atmosphere for $24 \mathrm{~h}$.

b THF was used as an oil phase, and a volume ratio of THF to water was equal to 0.07 .

respectively. The results, exhibited in Fig. 4, showed that both curves were almost overlapped. Weight loss of $10 \%$ was attributed to an elimination of water from both surfaces of $\mathrm{ZnO}$ nanoparticles and polyaniline $[5,9]$ when temperature was raised to ca $330^{\circ} \mathrm{C}$. Subsequently, there was a strong weight loss from 330 to ca $650^{\circ} \mathrm{C}$. It was due to degradation of polyaniline chains [5,9,31,32]. Finally, weight percentages of both residues were almost the same and nearly matched with the calculated contents of $\mathrm{ZnO}$ nanoparticles in formula. The above results indicated that both Pickering emulsions were stable in the polymerization and that the amount of $\mathrm{ZnO}$ nanoparticles, incorporated with polyaniline, and the thermal stability of the composite latex particles in both cases were nearly identical.

Influences of the $R$ values on the thermal properties of the composite latex particles, synthesized by using toluene as the oil phase, were also studied. The analyzed samples included the composite latex with $R=0.03$ and 0.07 and the suspension with $R=0.13$. The results are shown in Fig. 5. The graph trend for the composite latex with $R=0.03$ was considerably different from that with $R=0.07$. And in the case with $R=0.03$, weight percentage of the final residue was higher than the calculated content of $\mathrm{ZnO}$ nanoparticles in formula. It might be ascribed to an incomplete polymerization of aniline. For the suspension with $R=0.13$, the graph trend was similar to that of the composite latex with $R=0.07$, but the weight percentage of its final residue was slightly lower. It was attributed to the occurrence of phase separation. The volume fraction of the oil phase increased as $R$ increased. The total surface areas of the oil droplets thus increased considerably. Consequently, coverage of $\mathrm{ZnO}$ nanoparticles on the droplet surfaces was reduced. As a result, droplets and growing composite latex particles aggregated. When $R=0.13$, particle aggregation was so strong that phase separation was observed. The above results indicated once again that the stability of the Pickering emulsion was affected by the $R$ value.

\subsection{Influences of hydrophilicity of the oil phase on growth mechanism of composite latex particles}

The growth mechanism of the composite latex particles was, as mentioned above, strongly influenced by the hydrophilicity of the oil phase. When toluene was used as the oil phase, the oil droplets, stabilized by $\mathrm{ZnO}$ nanoparticles, were dispersed in the aqueous phase $[9,11]$ after miniemulsification. Since aniline and APS were dissolved in the droplets and the aqueous phase, respectively, aniline was polymerized under oxidation of APS on the interfaces of 
a
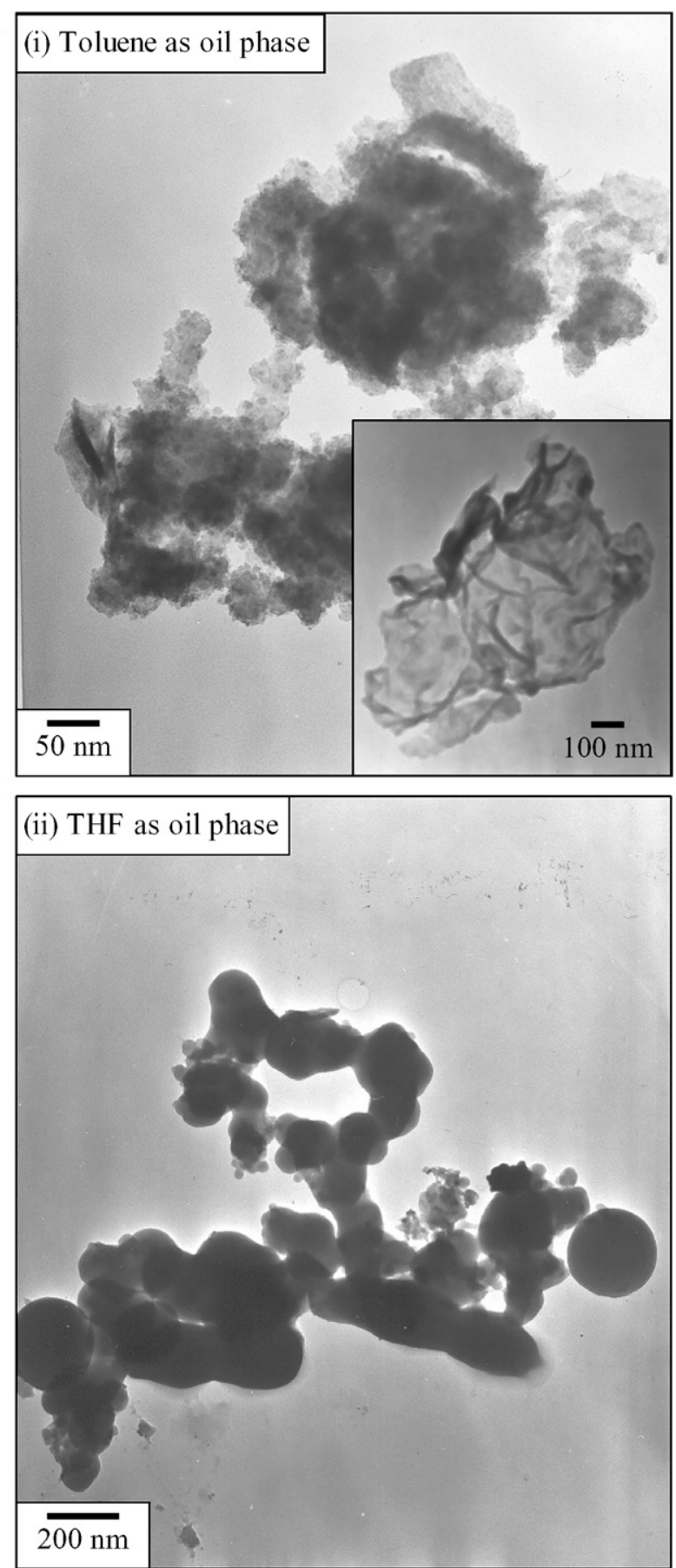

b

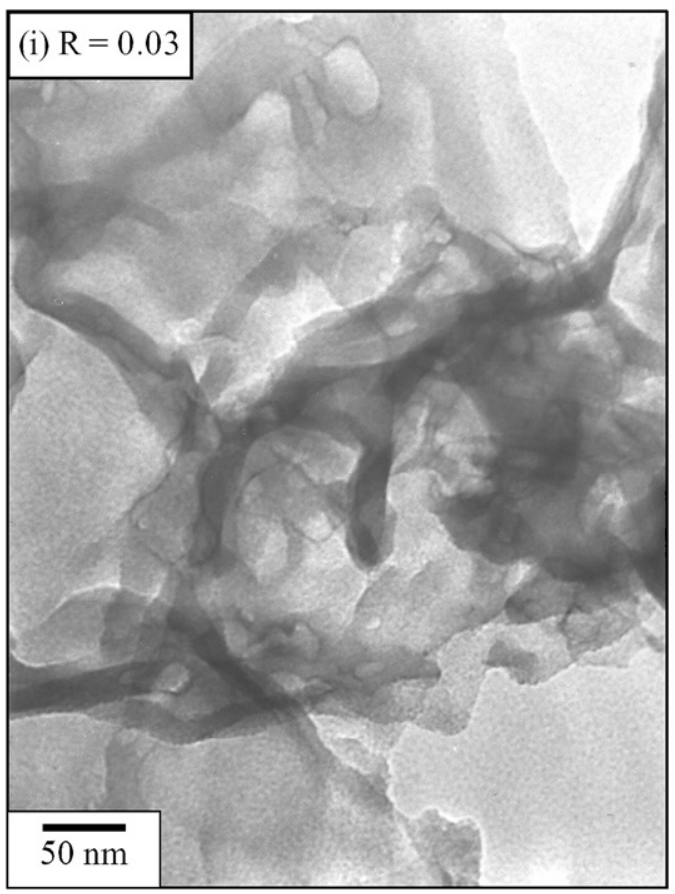

(ii) $\mathrm{R}=0.13$

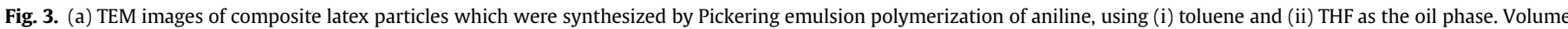

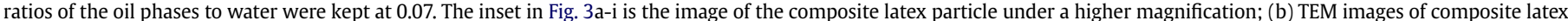
particles which were synthesized using (i) 0.03 and (ii) 0.13 of volume ratio of toluene/water as the oil phase.

the droplets/water [5,9,33]. The ZnO nanoparticles were 50$100 \mathrm{~nm}$ in size, relatively large in stabilizing the emulsion. They provided less total surface areas to cover the droplets. The droplets were, therefore, aggregated and squeezed in the polymerization to some extent. The composite latex particles with hollow structure, irregular morphology, and several hundred nanometers in size were thus resulted. Scheme 1 is proposed for the Pickering emulsion polymerization of aniline, using toluene as the oil phase.

While THF was used as the oil phase in the Pickering emulsion polymerization, growing particles of polyaniline were primarily produced from homogeneous nucleation in the aqueous phase. The nucleated particles of polyaniline were far smaller than the $\mathrm{ZnO}$ nanoparticles in size. ZnO nanoparticles then acted as templates for the nucleated particles. With growing in the volume of the polyaniline particles, coagulation occurred continuously to reduce the surface energy of the system. Finally, spherical latex particles, enwrapping $\mathrm{ZnO}$ nanoparticles, were thus formed. Scheme 2 is proposed to elucidate the Pickering emulsion polymerization of aniline, using THF as the oil phase.

The hydrophilicity of the oil phase influenced the growth mechanisms as described in Schemes 1 and 2. In brief, when the oil phase was very hydrophobic, polymerization system was mainly 


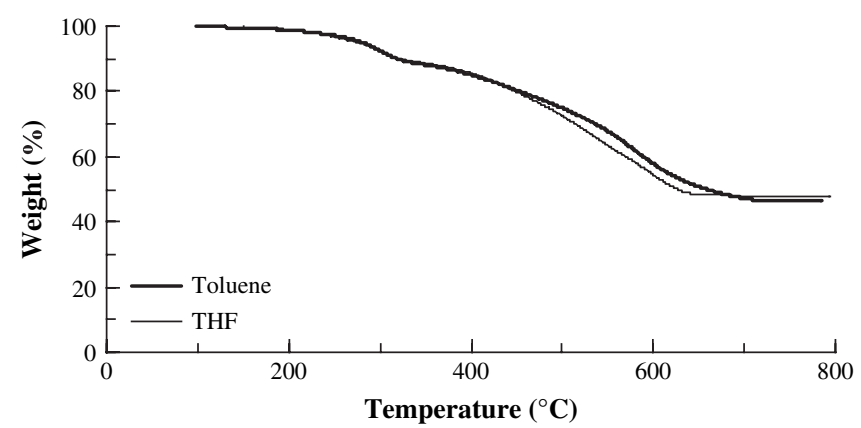

Fig. 4. TGA results of composite latex particles, synthesized by separately using toluene and THF as the oil phase.

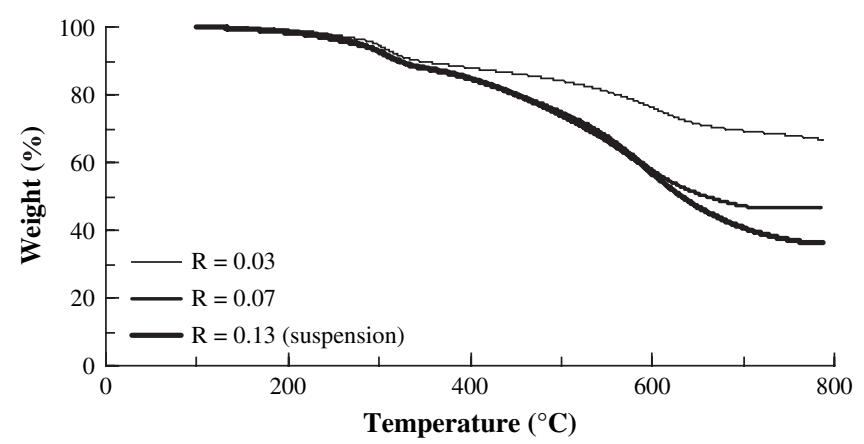

Fig. 5. TGA results of composite latex particles. The analyzed samples included the composite latex with $R=0.03$ and 0.07 and the suspension with $R=0.13$.

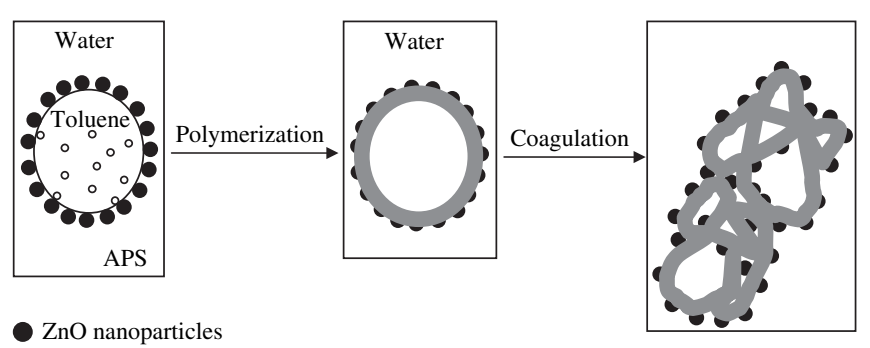

○ Aniline

- Polyaniline

Scheme 1. A proposed scheme for Pickering emulsion polymerization of aniline, using toluene as the oil phase.

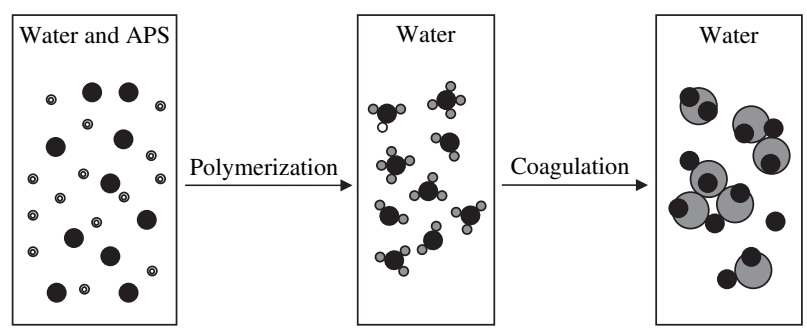

$\mathrm{ZnO}$ nanoparticles

- Aniline dissolved in THF

- Polyaniline

Scheme 2. A proposed scheme for Pickering emulsion polymerization of aniline, using THF as the oil phase. droplet nucleation, and the hollow composite latex particles were obtained. When the oil phase was very hydrophilic, polymerization system was mainly homogeneous nucleation, and solid spherical particles, enwrapping $\mathrm{ZnO}$ nanoparticles, were obtained.

Basically, two growth mechanisms (Schemes 1 and 2) were involved together in the system when an oil phase with the hydrophilicity between toluene and THF was used. PGMEA had been used as an oil phase in our study. The composite latex particles showed two kinds of morphologies, both hollow composite particles and solid spherical particles enwrapping $\mathrm{ZnO}$ nanoparticles.

For the systems separately using toluene and THF as the oil phase and having the volume ratios of toluene to water and THF to water at 0.07 , the morphologies of composite latex particles were very different due to their different growth mechanisms as mentioned previously. But compositions of reaction components in both systems, $\mathrm{ZnO}$ and aniline, were the same. Therefore, products of polyaniline/ZnO had almost the same composition as seen in Fig. 4. Analysis of Differential Scanning Calorimetry (DSC) had been done in our work. The DSC curve just showed a straight line. $T_{\mathrm{g}}$ of polyaniline was not detectable.

\subsection{Regulation of $\mathrm{pH}$ value by $\mathrm{ZnO}$ nanoparticles}

According to reports in literature [22,23], ZnO particles were soluble in both acidic and alkaline aqueous solutions because of the reactions with $\mathrm{H}^{+}$and $\mathrm{OH}^{-}$ions as below.

$\mathrm{ZnO}_{(\mathrm{s})}+2 \mathrm{H}^{+} \rightarrow \mathrm{Zn}^{2+}+\mathrm{H}_{2} \mathrm{O}$

$\mathrm{ZnO}_{(\mathrm{s})}+2 \mathrm{OH}^{-}+\mathrm{H}_{2} \mathrm{O} \rightarrow\left[\mathrm{Zn}(\mathrm{OH})_{4}\right]^{2-}$

It is interesting to study the pH-regulation capacity of ZnO nanoparticles in acidic and alkaline aqueous solutions. A series of experiments were conducted. Five stock aqueous solutions, each with $10 \mathrm{ml}$ in volume and different $\mathrm{pH}$ values, were separately mixed with $0.01 \mathrm{~g}$ of the $\mathrm{ZnO}$ nanoparticles by an ultrasonic device. Subsequently, the steady-state $\mathrm{pH}$ values of the stock solutions before and after addition of the $\mathrm{ZnO}$ nanoparticles were measured by a $\mathrm{pH}$ meter.

The results that the $\mathrm{ZnO}$ nanoparticles regulated the $\mathrm{pH}$ values of the stock solutions are exhibited in Fig. 6. The $X$ and $Y$ axes represented the $\mathrm{pH}$ values of stock solutions before and after addition of the $\mathrm{ZnO}$ nanoparticles, respectively. It depicted that the stock solutions, after addition of $\mathrm{ZnO}$, were kept at ca $\mathrm{pH} 7$ when they were ranged in $\mathrm{pH} \mathrm{3-8}$ before addition of the $\mathrm{ZnO}$ nanoparticles. However, the stock solutions could not be regulated to ca $\mathrm{pH} 7$ by the $\mathrm{ZnO}$ nanoparticles when they were in more basic condition $(\mathrm{pH}>8)$ initially. The above results indicated that the $\mathrm{pH}-$

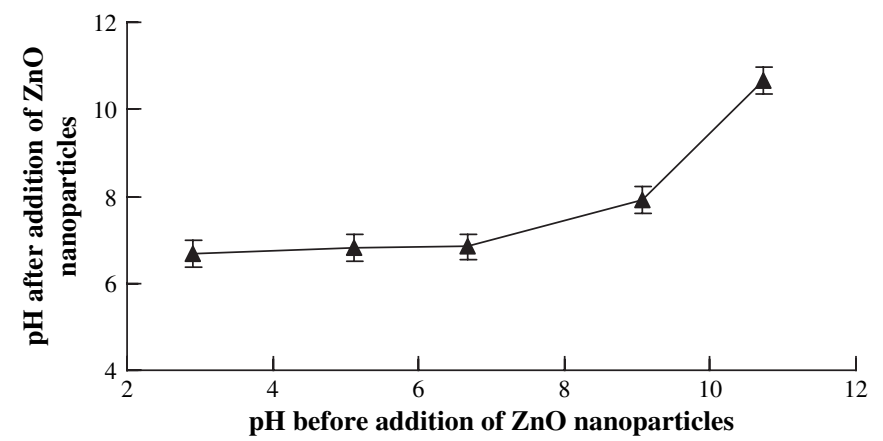

Fig. 6. The pH-regulation capacity of $\mathrm{ZnO}$ nanoparticles. 
regulation capacity of the $\mathrm{ZnO}$ nanoparticles was better for acidic stock solutions.

\subsubsection{PH-regulation capacity of composite latex particles}

Based on the results in Fig. 6, it is worth to study the capacity of the composite latex particles of polyaniline/ZnO in regulating $\mathrm{pH}$ values of the stock solutions. The composite latex, synthesized under different $R$ values, was studied, and results are shown in Fig. 7. As $R=0.03$ and 0.07 , the pH-regulation capacities of both composite latex particles were similar. The stock solutions, with $\mathrm{pH}$ 3-9 initially, were regulated to $\mathrm{ca} \mathrm{pH} 7$ by the composite latex particles. While the suspension, synthesized under $R=0.13$, was used to regulate the stock solutions, the $\mathrm{pH}$-regulation capacity of the suspension was limited to the stock solutions with $\mathrm{pH}$ 5-9 initially. The above results implied that the function of polyaniline on regulating $\mathrm{pH}$ values of the stock solutions was also important.

According to literature, peroxydisulfate ions could be decomposed into sulfate radicals and then into bisulfate ions in the aqueous phase [34-36]. The chemical reaction was described by the following equations [34,35].

$\mathrm{S}_{2} \mathrm{O}_{8}^{2-} \rightarrow 2 \mathrm{SO}_{4}^{\cdot-}$

$\mathrm{SO}_{4}^{-}+\mathrm{H}_{2} \mathrm{O} \rightarrow \mathrm{HSO}_{4}^{-}+\mathrm{HO}^{\cdot}$

Thus APS could simultaneously act as an oxidizing agent and a doping agent in the synthesis of conductive polymers, like polyaniline and poly(3,4-ethylenedioxythiophene) which were synthesized by an emulsion polymerization $[34,37,38]$. Based on the above results, we deduced that polymer chains had been doped by $\mathrm{H}^{+}$ions in the Pickering emulsion polymerization of aniline in our work. The results in Fig. 7 could thus be interpreted by the deduction.

For the cases of the composite latex which were synthesized under $R=0.03$ and 0.07 , regulating $\mathrm{pH}$ values of the stock solutions by addition of the composite latex particles was ascribed to both functions of the $\mathrm{ZnO}$ nanoparticles and polyaniline. As the stock solutions were initially in $\mathrm{pH} 3-8$, they were regulated to ca $\mathrm{pH} 7$ by mainly dissolution of the $\mathrm{ZnO}$ nanoparticles in the stock solutions. While they were initially in $\mathrm{pH} \mathrm{8-9,} \mathrm{neutralization} \mathrm{of} \mathrm{the} \mathrm{stock}$ solutions was mainly caused by dedoping of polyaniline. However, when the stock solution was initially over $\mathrm{pH} 9$, the $\mathrm{H}^{+}$ions, released from dedoping, were not enough to completely neutralize $\mathrm{OH}^{-}$ions in the stock solution. The more alkaline stock solution could not, consequently, be neutralized to ca $\mathrm{pH}$ 7. In short, regulating $\mathrm{pH}$ values of the stock solutions was contributed by the dissolution of the $\mathrm{ZnO}$ nanoparticles in the acidic aqueous solutions and dedoping of polyaniline in the alkaline ones.

For the case of the suspension which was synthesized under $R=0.13$, the stock solution, with ca $\mathrm{pH} 3$ initially, was not regulated to ca $\mathrm{pH} 7$ by addition of the suspension particles. It was attributed

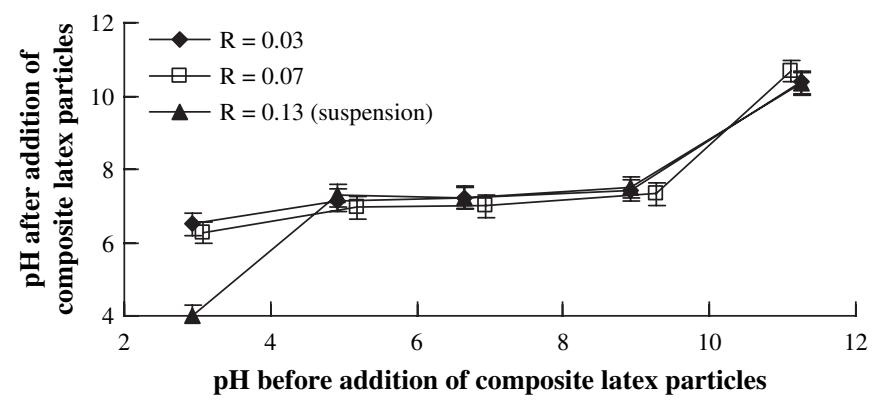

Fig. 7. The pH-regulation capacities of the composite latex particles, synthesized from different volume ratios of oil phase to water.

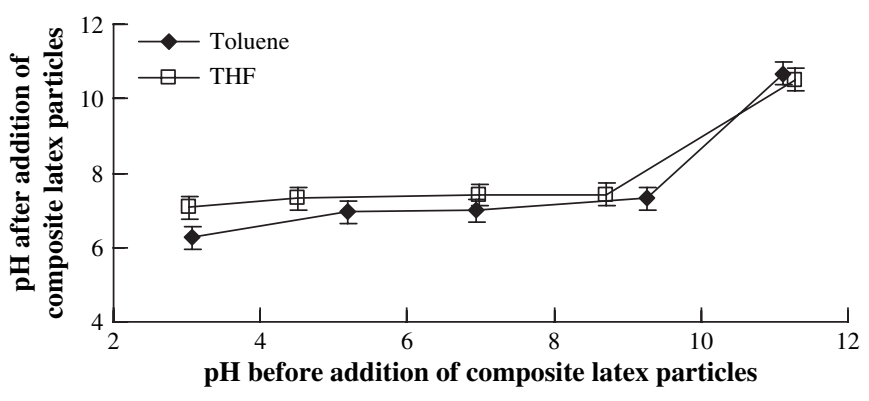

Fig. 8. The pH-regulation capacities of the composite latex particles, synthesized using different oil phases.

to deficiency in the amount of the $\mathrm{ZnO}$ nanoparticles in the suspension. The $\mathrm{ZnO}$ nanoparticles in the suspension were relatively low in quantity because of the occurrence of precipitation in the Pickering emulsion polymerization. They were not enough in amount to consume the $\mathrm{H}^{+}$ions in the more acidic stock solution. However, when the $\mathrm{H}^{+}$ions in the stock solutions, with $\mathrm{pH}$ 5-7 initially, were lower in concentration, the amounts of $\mathrm{ZnO}$ nanoparticles in the suspension were comparable with $\mathrm{H}^{+}$ions. The stock solutions, with pH 5-7 initially, could thus be regulated to ca $\mathrm{pH}$ 7. As the stock solutions were initially at ca $\mathrm{pH} 9$ or over 9, behavior of the suspension particles in regulating the stock solutions was close to that of the composite latex particles, synthesized under $R=0.03$ and 0.07 . Their curves were thus almost overlapped in this $\mathrm{pH}$ range.

The pH-regulation capacities of the composite latex particles, synthesized by using different oil phases, were also studied. Toluene and THF were separately used as the oil phase, and both the volume ratios of toluene to water and THF to water were kept at 0.07. The results, exhibited in Fig. 8, showed that the composite latex particles from THF had slightly better capacity in regulating $\mathrm{pH}$ values of the stock solutions. It indicated that the $\mathrm{ZnO}$ nanoparticles were more exposed on the surfaces of the composite particles in the system of THF. Fig. 9 shows the comparison of XRD spectra for the composite latex particles, synthesized by using different oil phases. The characteristic peaks of $\mathrm{ZnO}$ nanoparticles were much more clearly seen in the system of THF. The morphological difference originated from the different growth mechanism of the composite latex particles as indicated in Schemes 1 and 2.

Comparing Fig. 1 with Fig. 3a and Fig. 2 with Fig. 9, a morphological change and a slight shift in XRD characteristic peaks of the $\mathrm{ZnO}$ nanoparticles were observed after they experienced Pickering emulsion polymerization. The above results could be ascribed to the situations of the $\mathrm{ZnO}$ nanoparticles in the Pickering emulsion polymerization. The morphological change of the $\mathrm{ZnO}$ nanoparticles was caused by their partial dissolution in the course of the polymerization because of releasing $\mathrm{H}^{+}$ions in the decomposition of APS [34,35]. At the same time, crystal structure of the $\mathrm{ZnO}$

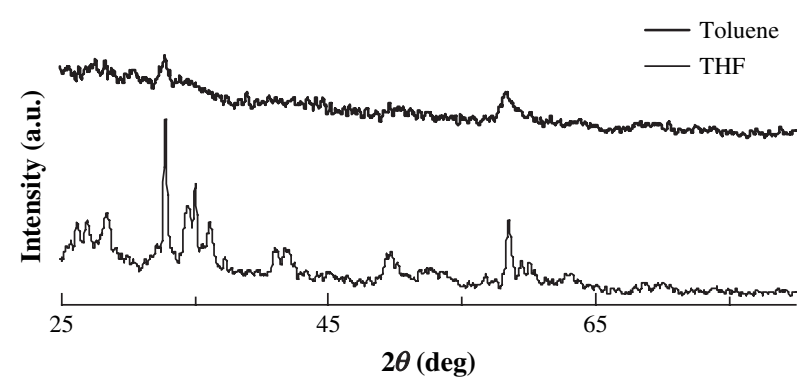

Fig. 9. X-ray diffraction spectra for the composite latex particles, synthesized using different oil phases. 
nanoparticles may be influenced. Thus their XRD characteristic peaks shifted slightly.

\section{Conclusions}

ZnO nanoparticles with polyhedral morphology and 50-100 nm in size had been prepared by precipitation from the aqueous phase. In the Pickering emulsion polymerization of aniline, using toluene as an oil phase, the composite latex particles with hollow and irregular morphology and hundreds of nanometer in size were resulted. It was ascribed to the polymerization of aniline on the interfaces of the droplets/water and the relatively large $\mathrm{ZnO}$ nanoparticles in stabilizing the emulsion.

When THF was used as an oil phase, coagulated latex particles, enwrapping $\mathrm{ZnO}$ nanoparticles, were obtained. It was attributed to the homogeneous nucleation of polyaniline in the aqueous phase. ZnO nanoparticles acted as templates.

Two growth mechanisms were proposed, Schemes 1 and 2, to elucidate the morphologies of the composite latex particles.

The stability of the Pickering emulsion polymerization was affected by the $R$ values, volume ratio of oil phase to water. The volume fraction and thus the total surface areas of the oil droplets increased with increasing $R$. The coverage of the $\mathrm{ZnO}$ nanoparticles on the droplets was thus reduced. The droplets and growing composite latex particles were, consequently, coagulated. As $R$ increased to 0.13 , particle coagulation was so strong that phase separation was observed.

The aqueous solution with $\mathrm{pH}$ 3-9 could simply be regulated to $\mathrm{pH} 7$ by the composite latex particles. It was contributed by the dissolution of the $\mathrm{ZnO}$ nanoparticles and doping-dedoping of polyaniline in the acidic and alkaline aqueous solutions.

\section{References}

[1] Xiao Q, Tan X, Ji L, Xue J. Synth Met 2007;157:784-91.

[2] He Y, Yu X. Mater Lett 2007;61:2071-4.
[3] Chen T, Colver PJ, Bon SAF. Adv Mater 2007;19:2286-9.

[4] Voorn DJ, Ming W, van Herk AM. Macromolecules 2006;39:2137-43.

[5] He Y. Appl Surf Sci 2005;249:1-6.

[6] Sullivan AP, Kilpatrick PK. Ind Eng Chem Res 2002;41:3389-404.

[7] Binks BP, Lumsdon SO. Langmuir 2000;16:2539-47.

[8] Giermanska-Kahn J, Schmitt V, Binks BP, Leal-Calderon F. Langmuir 2002;18: 2515-8.

[9] He Y. Powder Technol 2004;147:59-63.

[10] Cauvin S, Colver PJ, Bon SAF. Macromolecules 2005;38:7887-9.

[11] Binks BP, Lumsdon SO. Langmuir 2000;16:8622-31.

[12] Wu MM, Wang GG, Xu HF, Long JB, Shek FLY, Lo SMF, et al. Langmuir 2003;19: 1362-7.

[13] Zhang Y, Li G, Zhang L. Inorg Chem Commun 2004;7:344-6.

[14] Binks BP, Clint JH. Langmuir 2002;18:1270-3.

[15] Zhang Z, Wei Z, Wan M. Macromolecules 2002;35:5937-42.

[16] Yan N, Gray MR, Masliyah JH. Colloid Surf A Physicochem Eng Asp 2001;193: 97-107.

[17] Stejskal J, Trchová M, Blinova NV, Konyushenko EN, Reynaud S, Prokes J. Polymer 2008;49:180-5.

[18] Sudha JD, Sasikala TS. Polymer 2007;48:338-47.

[19] Li YQ, Fu SY, Mai YW. Polymer 2006;47:2127-32.

[20] Chiou NR, Epstein AJ. Adv Mater 2005;17:1679-83.

[21] Quadrat OO, Stejskal J, Kratochvil P, Klason C, McQueen D, Kub'at J, et al. Synth Met 1998;97:37-42.

[22] Yebra DM, Kiil S, Weinell CE, Johansen KD. Prog Org Coat 2006;56:327-37.

[23] Meulenkamp EA. J Phys Chem B 1998;102:7764-9.

[24] Pesika NS, Stebe KJ, Searson PC. J Phys Chem B 2003;107:10412-5.

[25] Bahnemann DW, Kormann C, Hoffmann MR. J Phys Chem 1987;91: 3789-98.

[26] Pesika NS, Hu Z, Stebe KJ, Searson PC. J Phys Chem B 2002;106:6985-90.

[27] Hu Z, Oskam G, Penn RL, Pesika N, Searson PC. J Phys Chem B 2003;107: 3124-30.

[28] Guo L, Yang S, Yang C, Yu P, Wang J, Ge W, et al. Chem Mater 2000;12:2268-74.

[29] Ma J, Jiang C, Xiong Y, Xu G. Powder Technol 2006;167:49-53.

[30] He Y. Mater Chem Phys 2005;92:609-12.

[31] Kim BH, Jung JH, Hong SH, Joo J, Epstein A, Mizoguchi K, et al. Macromolecules 2002;35:1419-23.

[32] Kumar RV, Mastai Y, Gedanken A. Chem Mater 2000;12:3892-5.

[33] Huang J, Kaner RB. J Am Chem Soc 2004;126:851-5.

[34] Seo KI, Chung IJ. Polymer 2000;41:4491-9.

[35] House DA. Chem Rev 1962;62:185-203.

[36] Farcet C, Lansalot M, Charleux B, Pirri R, Vairon JP. Macromolecules 2000;33: 8559-70.

[37] Palaniappan S, Saravanan C, John A. J Macromol Sci Part A Pure Appl Chem 2005;42:891-900.

[38] Palaniappan S. Polym Adv Technol 2002;13:54-9. 